\title{
Development of the Dimensional Clinical Personality Inventory - Avoidant version based on the HiTOP
}

\author{
Lucas de Francisco Carvalho ${ }^{1}$, Adriana Satico Ferraz, Fernanda Otoni \\ Universidade São Francisco, Campinas-SP, Brasil
}

\begin{abstract}
This study aimed to develop a specific version of the Dimensional Clinical Personality Inventory 2 (IDCP-2), focused on the assessment of avoidant personality disorder (AvPD) according to the Hierarchical Taxonomy of Psychopathology (HiTOP). First, we developed the IDCP-Av, composed of one new factor and four factors from the IDCP-2. A total of 436 adults completed this, and two external measures (PID-5 and FFAvA). The IDCP-Av factors and its total score presented high reliability. Correlations and group comparisons were coherent, corroborating expectations. Favorable evidence was observed for the use of the IDCP-Av for the measurement of $\mathrm{Av} \mathrm{PD}$, although future studies should replicate the findings in samples composed of patients.

Keywords: personality disorders; personality assessment; dimensional model; cluster C; psychometrics.
\end{abstract}

\begin{abstract}
RESUMO - Desenvolvimento do Inventário Dimensional Clínico da Personalidade - Versão Evitativo Baseado no HiTOP

O objetivo deste estudo foi desenvolver uma versão específica do Inventário Dimensional Clínico da Personalidade 2 (IDCP-2), focada na avaliação do transtorno da personalidade evitativo (TPE) de acordo com o Hierarchical Taxonomy of Psychopathology (HiTOP). Primeiro foi desenvolvido o IDCP-Av, composto por um novo fator e quatro fatores do IDCP-2. 436 adultos responderam-no, além de medidas externas (PID-5 e FFAvA). Os fatores do IDCP-Av e o escore total apresentaram alta precisão. Correlações e comparações entre grupos foram coerentes e corroboraram as expectativas. Evidências favoráveis foram observadas para o uso do IDCP-Av para avaliação do TPE, embora futuros estudos devem tentar replicar os achados em amostras compostas por pacientes.

Palavras-chave: transtornos da personalidade; avaliação da personalidade; modelo dimensional; cluster C; psicometria.
\end{abstract}

RESUMEN - Desarrollo del Inventario Dimensional Clínico de la Personalidad - Versión Evitativa basada en el HiTOP

El objetivo de este estudio fue desarrollar una versión específica del Inventario Dimensional Clínico de la Personalidad 2 (IDCP-2), centrado en la evaluación del trastorno de la personalidad evitativa (TPE) de acuerdo con el Hierarchical Taxonomy of Psychopathology (HiTOP). Primeramente se desarrolló el IDCP-Av, compuesto por un nuevo factor y por cuatro factores del IDCP-2. 436 adultos lo contestaron juntamente con medidas externas (PID-5 y FFAvA). Los factores IDCP-Av y su puntuación total presentaron una alta fiabilidad. Las correlaciones y las comparaciones de los grupos fueron coherentes, corroborando con las expectativas. Se observaron evidencias favorables para el uso del AvPD-Av para evaluar el TPE. Sin embargo, estudios posteriores deberían replicar los hallazgos presentes en muestras compuestas por pacientes.

Palabras-clave: trastornos de personalidad; evaluación de la personalidad; modelo dimensional; cluster C; psicometría.

Debate on the best way to assess and diagnoses of personality disorders (PD) is not new (Forbes et al., 2017; Hopwood et al., 2018; Kotov et al., 2017). Briefly, the categorical perspective is the official approach (American Psychological Association [APA], 2013), and the dimensional perspective represents one of the leading alternative approaches to replace it (Huprich, 2018). The categorical view proposes a dichotomous diagnosis according to a minimal number of symptoms (Anderson et al., 2012; Hopwood, Thomas, Markon, Wright, \& Krueger, 2012; Skodol, Morey, Bender, \&
Oldham, 2015). This approach is a target of several criticisms, which are reviewed as discussed in the previous literature (Esebec \& Echeburúa, 2015; Sarkar \& Duggan, 2010; Skodol et al., 2011; Zimmerman, 2011). Contrasting with this view, the dimensional perspective performs the assessment of pathological traits in a continuum (Hopwood et al., 2018; Krueger \& Markor, 2014; Morey, Benson, \& Skodol, 2016), including a higher number of traits related to PDs in comparison with the categorical approach (Anderson, Snider, Sellbom, Krueger, \& Hopwood, 2014; Carvalho \& 
Primi, 2016; Forbes et al., 2017; Krueger \& Markor, 2014; Millon, 2011).

The limitations of the categorical perspective and suitable evidence of the dimensional approach guided Kotov et al. (2017) in the development of the Hierarchical Taxonomy of Psychopathology (HiTOP). This taxonomic proposal intends to overcome some inconsistencies identified in the traditional classifications of mental disorders and, specifically PDs, although empirical evidence is just initial (see Maj, 2018). In broad lines, the HiTOP aims to reduce heterogeneity grouping symptoms and traits according to covariation between psychopathologies included in the model. Moreover, the HiTOP was organized in spectra, combining co-occurring symptoms and traits in an attempt to reduce comorbidity. The HiTOP characteristics were planned in a dimensional understanding and should minimize diagnostic instability (Kotov et al., 2017). Our focus in the present work in one of the PDs included in the HiTOP, the avoidant personality disorder (AvPD).

AvPD refers to people that avoid the proximity of other people in almost all situations (APA, 2013). An individual with AvPD expresses pathological fear of being ridiculed by people, feeling of inadequacy, low self-esteem, a sense of inferiority, and get easily hurt in their feelings (Krueger, Derringer, Markon, Watson, \& Skodol, 2012; Lampe \& Malhi, 2018). Due to these characteristics, people high in AvPD traits typically are limited to close relationships only, presenting great difficulties in interpersonal relationships bounds (Sellbom, Carmichael, \& Liggett, 2017). The AvPD is considered as a chronic and long-term condition, usually early manifested (Lampe \& Malhi, 2018; Weinbrecht, Schulze, Boettcher, \& Renneberg, 2016).

Under the HiTOP perspective, the AvPD is part of the Detachment spectrum, including traits as anhedonia, depressivity, intimacy avoidance, suspiciousness, withdrawal, interpersonal passivity, disaffiliativeness, and low attention-seeking. As the Detachment spectrum includes schizoid, histrionic, and dependent PDs (Kotov et al., 2017), not necessarily all traits from this spectrum apply to the AvPD.

According to Kotov et al. (2017), many assessment tools comprise traits from the HiTOP. For instance, and strictly related to AvPD, the Five-Factor Measure of Avoidant Personality - FFAvA (Lynam, Loher, Miller, \& Widiger, 2012) presents factors developed to measure AvPD traits (e.g., evaluation apprehension) directly. Not related explicitly to the AvPD, but including its traits, the Minnesota Multiphasic Personality Inventory-2 (MMPI-2; Butcher et al., 2001) includes social introversion and shyness factors, as well as the Personality Inventory for DSM-5 (PID-5; Krueger et al., 2012), composed by intimacy avoidance and withdrawal factors. We highlight that the present study was conducted in Brazil, the context in which the majority if assessment tools presented by Kotov et al. (2017) are not available.

In the Brazilian reality, one of the few available selfreport scales for pathological personality traits assessment is the Dimensional Clinical Personality Inventory (IDCP; Carvalho \& Primi, 2015), and its reviewed version, the IDCP-2 (Carvalho \& Primi, 2019), updated according to the traits of the alternative model for PDs (APA, 2013; Krueger et al., 2012), in addition to other resources (e.g., Shedler \& Western, 2004; Clark, 1990). There is evidence suggesting the accordance between IDCP-2 factorial structure with the spectra structure from the HiTOP (Pianowski, Carvalho, \& Miguel, 2019). Regarding the AvPD, IDCP-2 and its previous version combine several traits that represent the core of this $\mathrm{PD}$, showing good discriminant and predictive capacities (Abela, Carvalho, Cho, \& Yazigi, 2015; Carvalho \& Sette, 2017; Carvalho, Sette, \& Miguel, 2018). In general, evidence from these studies suggest the Criticism avoidance dimension as relevant for AvPD traits assessment, as well as some factors from Isolation and SelfSacrifice dimensions.

The IDCP-2 coverage of the AvPD was presented in previous literature, although some traits listed in the HiTOP as relevant to this PD are not represented in the evaluative content that composes the instrument. This study aimed to develop a specific version of the IDCP-2 (i.e., IDCP Avoidant Personality Disorder Scale; IDCPAv) focused on the assessment of traits related to AvPD in accordance with the HiTOP. Moreover, we verified the psychometric properties of the IDCP-Av, aiming to establish its reliability and present initial validity evidence, seeking indicators of the pertinence of the scale in measuring AvPD traits.

\section{Methods}

This section was split into two steps. Step 1 refers to the procedures for the development of the IDCP-Av, a self-report measure focusing on the evaluation of typical HPD traits according to HiTOP. Step 2 is focused on the verification of the psychometric properties of the IDCPAv on a community sample.

\section{Step 1 - Development of the IDCP Avoidant Personality Disorder Scale (IDCP-Av) according to HiTOP}

\section{Procedures}

At first, we selected only spectra of HiTOP, including AvPD. Relevant traits for AvPD were selected, deliberately attempting to maintain as many traits as possible, aiming at the representativeness of typical AvPD traits. Accordingly, we searched for traits definitions in the literature, mainly according to the measurement tests mentioned in Table 1 of Kotov et al. (2017). We used 
definitions from MMPI-2, PID-5, and FFAvA (Butcher et al., 2001, Krueger, 2012; Lynam et al., 2012). Then, IDCP-2 factors representing relevant AvPD traits were selected. We identified that some traits considered as relevant were did not cover by any IDCP-2 factors. These traits were operationalized in self-report items, i.e., we created new items for representing traits not covered by any factor from IDCP-2. Items development was conducted independently by the authors. The most suitable items were selected by consensus according to its content and semantic characteristics. Specifically, clarity (showing information directly transmitted), content (presenting information relevant to the construct), and (non-) redundancy (avoiding items with ambiguous or repeated information) of the items were verified. At the end of this step, the administration version of the IDCP-Av was produced, and subjected to the empirical verification, as described in Step 2.

\section{Step 2 - Psychometric study of the IDCP Avoidant Personality Disorder Scale (IDCP-Av)}

\section{Participants}

Data collection was by convenience sampling, a procedure largely used with community samples in studies on pathological traits (Huprich, 2018). The sample was composed of 436 people from the community. The participants aged from 18 and 67 years $(M=31.6, S D=9.7)$ and were mainly female (66.7\%), Caucasian (76\%), and mostly reporting more than 10 years of education (49.2\%). 47.6\% reported having attended psychotherapy and $19.6 \%$ to psychiatric treatment. Some participants reported past suicidal ideation (36.2\%), suicide attempts $(6.3 \%)$, and currently suicidal ideation (5\%). Based on this information, although being a community sample, the occurrence of AvPD traits was likely.

The expectation for AvPD occurrence in community samples is about $2.4 \%$ (APA, 2013). In an epidemiologic study in the São Paulo Metropolitan Area, Brazil, $4.6 \%$ of cases of PD from Cluster C were observed (Santana et al., 2018). According to this, for the present study, people with elevation in typical traits of the AvPD were expected, although a small number of people with AvPD diagnosis should be found.

\section{Measures}

The IDCP Avoidant Personality Disorder Scale, IDCP-Av, is a scale originated from de Dimensional Clinical Personality Inventory 2 (IDCP-2; Carvalho \& Primi, 2019) based on the traits of the AvPD according to the HiTOP (Kotov et al., 2017; Conway et al., 2019). The IDCP-2 consists of a self-report measure developed for the assessment of pathological personality traits, comprising 206 items on a Likert 4-point scale, from "has nothing to do with me" to "everything to do with $m e "$. The IDCP-2 covers 47 factors on 12 dimensions (i.e., Dependency, Aggressiveness, Mood Instability, Eccentricity, Attention Seeking, Distrust, Grandiosity, Isolation, Criticism Avoidance, Self-sacrifice, Conscientiousness, and Inconsequence). For this study, we administered four factors from three dimensions, totalizing 22 items: Isolation dimension (social isolation factor; Carvalho \& Arruda, 2016), Criticism avoidance dimension (generalized avoidance and intimate relationships avoidance factors; (Carvalho \& Sette, 2017), and Self-sacrifice dimension (depressivity factor; Carvalho \& Silva, 2016). Added to this, the IDCP-Av version is also composed of the new interpersonal passivity factor, best described further in this paper.

The Personality Inventory Disorder for DSM-5 (PID-5; Krueger et al., 2012) is a self-report inventory to the assessment of 25 facets representing pathological characteristics of personality according to the Alternative Model for Personality Disorders (AMPD) of the DSM-5 (APA, 2013). It contains 220 items on a Likert 4-point scale, from "false or often false" to "true or often true". The 25 facets are grouped into five dimensions (i.e., Negative Affect, Detachment, Antagonism, Disinhibition, and Psychoticism). For this study, we selected the following facets: anhedonia $(\alpha=0.88)$, intimacy avoidance $(\alpha=0.84)$, restricted affectivity ( $\alpha=0.75)$, and withdrawal $(\alpha=0.93)$. Satisfactory psychometric properties for the PID-5 were previously published (Krueger et al., 2012; Al-Dajani, Gralnick \& Bagby, 2016).

The Five-Factor Model Personality Disorder scales (FFM-PD scales; Widiger \& Costa Junior, 2013; Widiger, Lynam, Miller, \& Oltmanns, 2012) aim to evaluate pathological traits based on the Five-Factor model and is composed by five domains assessing 99 traits. Items must be answered on a Likert 5-point scale ranging from "strongly disagree" to "strongly agree". The FFM-PD have shown satisfactory psychometric properties (DeShong, Lengel, Sauer-Zavala, O'Meara, \& Mullins-Sweatt, 2015; Gore, Tomiatti, \& Widiger, 2011; Mullins-Sweatt et al., 2012; Tomiatti, Gore, Lynam, Miller, \& Widiger, 2012; Widiger et al., 2012). For this study, we included two factors (14 items) from the Five-Factor Avoidant Assessment (FFAvA; Lynam et al., 2012) focused on the AvPD symptoms, specifically, joylessness $(\alpha=0.82)$ and evaluation apprehension $(\alpha=0.79)$.

\section{Procedures}

This study followed the ethical research procedures following the Declaration of Helsinki (World Medical Association, 2013) and was conducted under the approval of the Brazilian Research Ethics Committee (CAAE: 21992113.1.0000.5514). We performed online data collection using Google Forms, inviting volunteers through social networking sites (e.g., Facebook). The protocol comprised a term to attest the voluntary participation, followed by demographic data and the tests. The volunteers dedicated approximately 30 minutes to respond to 
the survey. After four weeks of data collection, we extracted the database for analyses.

\section{Data analyzes}

According to the aim of this study, in step 1 we selected the relevant traits for the AvPD, according to HiTOP (see Table 1). According to it, new items were developed and grouped in factors, achieving the version to the administration of the IDCP-Av. Psychometric properties were verified in step 2 through the exploratory structural equation modeling (E-SEM), using parallel analysis as an indicator of the number of factors. Internal consistency and intracorrelations were calculated as indicators of reliability. Correlations were performed between the IDCP-Av factors and the respective external measures. We also proceeded to bootstrap $(k=10.000$; bias-corrected $95 \%$ confidence intervals $C I)$ two-sample t-test, including the Levene's test for equality of variances, creating two groups from total sample: healthy group $(n=213)$, composed by people that related never having done psychotherapy and psychiatric treatment, as well reported no suicidal attempt and suicidal thoughts, and pathological group $(n=74)$, composed by people that reports having psychiatric diagnosis and participate on psychiatric treatment. We use R software version 3.4.0 for parallel analysis calculation, MPlus software version 7 for E-SEM, and SPSS software version 21 for reliability, correlations, and test $\mathrm{t}$ with bootstrap. P-value level was $\leq .05$.

\section{Results}

\section{Step 1 - IDCP-2 revision procedures according to pathological traits from spectra of the HiTOP model}

Table 1 presents the spectra related to AvPD from HiTOP model, as well as the traits composing these spectra, relevant traits for AvPD selected independently by the authors of this research, and the external measures respective for each IDCP-2 factors and new factors.

Table 1

Spectra, Traits, Relevant Traits, IDCP-2 Factors and Developed Factors, and External Measures

\begin{tabular}{|c|c|c|c|c|}
\hline Spectrum & Traits & Relevant traits & IDCP-2 factors & External measures \\
\hline \multirow{11}{*}{$\mathrm{D}$} & & \multirow{6}{*}{$\begin{array}{c}\text { Anhedonia } \\
\text { Intimacy avoidance } \\
\text { Withdrawal } \\
\text { Interpersonal } \\
\text { passivity }\end{array}$} & Depressivity & Anhedonia* \\
\hline & & & Generalized avoidance & Joylessness** \\
\hline & $\begin{array}{c}\text { Anhedonia } \\
\text { Intimacy avoidance }\end{array}$ & & $\begin{array}{l}\text { Intimate relationships } \\
\text { avoidance }\end{array}$ & \\
\hline & Withdrawal & & $\begin{array}{c}\text { avolaance } \\
\text { Generalized avoidance }\end{array}$ & Withdrawal* \\
\hline & Interpersonal passivity & & Social isolation & $\mathrm{EA}^{* *}$ \\
\hline & Disaffiliativeness & & $\begin{array}{l}\text { Soclal isolation } \\
\text { Internersonal passivity }\end{array}$ & Withdrawal* \\
\hline & $\begin{array}{c}\text { Disathliativeness } \\
\text { Depressivity }\end{array}$ & Disaffiliativeness & $\begin{array}{l}\text { Interpersonal passivity } \\
\text { (12 items } \rightarrow 4 \text { items) }\end{array}$ & Joylessness ${ }^{* *}$ \\
\hline & Suspiciousness & - & Generalized avoidance & $\mathrm{RA}^{*}$ \\
\hline & & - & - & - \\
\hline & & - & - & - \\
\hline & & & - & - \\
\hline
\end{tabular}

Note. In bold are the new factor developed in this study. In the brackets (penultimate column) are presented the number of items developed and selected for empirical research (step 2). ${ }^{*}=$ factor from PID-5; ${ }^{* *}=$ factor from FFaVa; D=Detachment; EA=Evaluation apprehension; RA=Restricted affectivity

From the detachment spectrum, five traits were judged as relevant for the AvPD. From these traits, items for Interpersonal passivity were created, as no factor from IDCP-2 covered this trait. Therefore, seeking to cover all traits, 12 items for one factor were created, and six were selected for administration in Stage 2. Items that were selected contemplated the criteria for clarity, consistency, content, and (non-)redundancy. Specifically, regarding content, the items should present an unambiguous relationship with the definition of the trait (Smith \& McCarthy, 1995). The new factor was labeled as Interpersonal passivity, directly reflecting the trait from HiTOP model. The IDCP-Av was composed by 26 items distributed in five factors, and it was administered in step 2 .

\section{Step 2 - Psychometric properties of the IDCP-Av}

Descriptive information is presented in Table 2. We investigated the psychometric properties of the item set, starting from the parallel analysis for polychoric variables, determining the maximum number of factors for the test. We obtained up to one factor, with significant eigenvalues not randomly established, and proceeded the exploratory structural equation modeling 
(E-SEM; Marsh, Morin, Parker, \& Kaur, 2014), forcing the one-factor solution, using the Geomin oblique rotation and extraction method Maximum Likelihood Robust (MLR), considered as a robust method suitable for polychoric variables.

The evaluation of the fit indices indicated the following interpretation: poor for RMSEA (0.11), good for CFI (0.92), and good for SMR (0.05), according to Hooper, Coughlan and Mullen (2008). Table 3 shows factors loadings, an average of the correlations between the measures composing the factor, internal consistency (Cronbach's $\alpha$ ) for measures and factor, and communalities.

Table 2

Descriptive Results of Total Scores of Measures

\begin{tabular}{|c|c|c|c|c|c|c|c|}
\hline Scales & Measures & Minimum & Maximum & Mean & $\mathrm{SD}$ & Skewness & Kurtosis \\
\hline \multirow{4}{*}{$\begin{array}{l}\stackrel{N}{1} \\
\stackrel{\prime}{u} \\
\varrho\end{array}$} & Generalized avoidance & 1.00 & 4.00 & 1.6321 & .63811 & 1.192 & .921 \\
\hline & Intimate relationships avoidance & 1.00 & 4.00 & 1.4600 & .69987 & 1.736 & 2.501 \\
\hline & Social isolation & 1.00 & 3.75 & 1.8144 & .62835 & .437 & -.594 \\
\hline & Depressivity & 1.00 & 4.00 & 1.8097 & .87524 & 1.013 & .007 \\
\hline 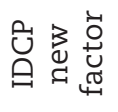 & Interpersonal passivity & 1.00 & 4.00 & 2.0383 & .81785 & .570 & -.520 \\
\hline \multirow{4}{*}{ 占 } & Anhedonia & 1.13 & 3.88 & 1.9197 & .47774 & 1.123 & 1.172 \\
\hline & Intimacy Avoidance & 1.00 & 3.50 & 1.5088 & .51626 & 1.442 & 2.060 \\
\hline & Withdrawal & 1.00 & 4.00 & 1.7211 & .61998 & 1.119 & .984 \\
\hline & Restricted Affectivity & 1.00 & 4.00 & 1.7834 & .69988 & .891 & .226 \\
\hline \multirow{2}{*}{$\sum_{\text {出 }}^{\infty}$} & Joylessness & 1.00 & 5.00 & 2.0087 & .86640 & 1.191 & 1.355 \\
\hline & Evaluation Apprehension & 1.00 & 5.00 & 2.54 & 1.087 & .401 & -.764 \\
\hline
\end{tabular}

Note. $S D=$ standard deviation

Table 3

Factor Loadings of the Factors Composing the IDCP-Av

\begin{tabular}{cccc}
\hline Measures & $\alpha$ & Interpersonal Avoidance & Communalities \\
\hline Generalized avoidance & .85 & 0.90 & .75 \\
Intimate relationships avoidance & .89 & 0.34 & .17 \\
Social isolation & .76 & 0.48 & .26 \\
Interpersonal passivity & .82 & 0.18 & .03 \\
Depressivity & .90 & 0.72 & .48 \\
& & $.26(.38)$ & $.63(.70)$ \\
\hline
\end{tabular}

Note. ${ }^{\text {a }}$ developed measure. In brackets, the average of the correlations and the reliability without the Interpersonal passivity factor

Almost all measures showed internal consistency higher than .80 , but Social isolation. As the average correlations of measures suggested poor to moderate relationship between variables, we proceed to verifications in order to identify if some of the factors were lowering these results. What we found was that the new factor, Interpersonal passivity, despite showing high reliability, was poorly correlated with the other factors (from .04 to .18), affecting the reliability of the higher-order factor (i.e., Interpersonal Avoidance) and the average correlation between the factors. We are also presenting the communalities, another indicator that the Interpersonal passivity factor is not enough correlated with the other factors. Therefore, we are presenting in Table 3 the average correlation and the reliability without the Interpersonal passivity factor. Table 4 presents the correlations between IDCP-Av factors with the PID-5 and FFAVA factors administered. 
Table 4

Correlations between IDCP-Av Factors with PID-5 and FFaVA

\begin{tabular}{lcccccc}
\hline & Anhedonia & $\begin{array}{c}\text { Intimacy } \\
\text { Avoidance }\end{array}$ & Withdrawal & $\begin{array}{c}\text { Restricted } \\
\text { Affectivity }\end{array}$ & $\begin{array}{c}\text { Joylessness } \\
\text { Apprehension }\end{array}$ \\
\hline Depressivity & $.24^{* *}$ & .06 & $.20^{* *}$ & $.11^{*}$ & $.21^{* *}$ & $.17^{* *}$ \\
Intimate relationships avoidance & $.11^{*}$ & $.30^{* *}$ & $.23^{* *}$ & $.23^{* *}$ & .04 & .09 \\
Generalized avoidance & $.27^{* *}$ & $.11^{*}$ & $.27^{* *}$ & $.17^{* *}$ & $.17^{* *}$ & $.20^{* *}$ \\
Social isolation & .07 & $.10^{*}$ & $.20^{* *}$ & $.16^{* *}$ & .03 & .01 \\
Interpersonal passivity & $.25^{* *}$ & $.11^{*}$ & $.36^{* *}$ & $.20^{* *}$ & .06 & $.20^{* *}$ \\
Interpersonal Avoidancea & $.31^{* *}$ & $.21^{* *}$ & $.40^{* *}$ & $.27^{* *}$ & $.17^{* *}$ & $.22^{* *}$ \\
\hline
\end{tabular}

Note. ${ }^{a}$ higher-order factor (according to Table 3). In bold, the correlations between IDCP-Av factors and the respective external measure, according to Table $1 .{ }^{* *}$ Correlation is significant at the 0.01 level; ${ }^{*}$ Correlation is significant at the 0.05 level

The expected correlations were observed, i.e., larger effect sizes were found with the corresponding measures. We can observe that, as the factor Generalized avoidance from IDCP-Av is related to several traits selected from Detachment spectrum, almost all effects for this factor are bolded in Table 4. In some cases, despite being the higher effect, the expected relationship showed only a small to moderate correlation. Moreover, although the Interpersonal passivity factor has shown a poor relationship with other factors (Table 3), its association with the expected factor (i.e., Withdrawal) was observed. Regarding the higher-order factor, it's correlated more with Withdrawal from PID-5 and less with Intimacy avoidance (PID-5) and Evaluation Apprehension (FFaVA). Table 5 presents results on healthy and pathological groups comparison.

Table 5

Comparison between pathological $(n=74)$ and healthy $(n=213)$ groups in factors from IDCP-Av

\begin{tabular}{|c|c|c|c|c|c|c|c|c|}
\hline \multirow{2}{*}{ Factors } & \multirow{2}{*}{ Groups } & \multirow{2}{*}{ Mean } & \multirow{2}{*}{ SD } & \multicolumn{2}{|c|}{ BCa 95\% CI } & \multirow{2}{*}{$t$} & \multirow{2}{*}{$d f$} & \multirow{2}{*}{$p(d)$} \\
\hline & & & & Lower & Upper & & & \\
\hline \multirow{2}{*}{ Depressivity } & - & 1.96 & 0.87 & 1.78 & 2.16 & \multirow{2}{*}{2.341} & \multirow{2}{*}{285} & \multirow{2}{*}{$.02(0.31)$} \\
\hline & + & 1.70 & 0.83 & 1.60 & 1.81 & & & \\
\hline \multirow{2}{*}{ Intimate relationships avoidance } & - & 1.42 & 0.68 & 1.28 & 1.58 & \multirow{2}{*}{-.451} & \multirow{2}{*}{285} & \multirow{2}{*}{$.65(0.06)$} \\
\hline & + & 1.46 & 0.70 & 1.37 & 1.56 & & & \\
\hline \multirow{2}{*}{ Generalized avoidance } & - & 1.78 & 0.73 & 1.62 & 1.96 & \multirow{2}{*}{2.418} & \multirow{2}{*}{285} & \multirow{2}{*}{$.02(0.33)$} \\
\hline & + & 1.57 & 0.61 & 1.49 & 1.66 & & & \\
\hline \multirow{2}{*}{ Social isolation } & - & 1.83 & 0.64 & 1.68 & 1.98 & \multirow{2}{*}{.123} & \multirow{2}{*}{285} & \multirow{2}{*}{$.90(0.02)$} \\
\hline & + & 1.82 & 0.64 & 1.72 & 1.91 & & & \\
\hline \multirow{2}{*}{ Interpersonal passivity } & - & 2.16 & 0.81 & 1.98 & 2.33 & \multirow{2}{*}{1.741} & \multirow{2}{*}{285} & \multirow{2}{*}{$.08(0.24)$} \\
\hline & + & 1.97 & 0.79 & 1.86 & 2.07 & & & \\
\hline \multirow{2}{*}{ Interpersonal Avoidance ${ }^{a}$} & - & 1.83 & 0.47 & 1.72 & 1.94 & \multirow{2}{*}{1.989} & \multirow{2}{*}{285} & \multirow{2}{*}{$.04(0.28)$} \\
\hline & + & 1.70 & 0.47 & 1.64 & 1.77 & & & \\
\hline
\end{tabular}

Note. - =pathological group; + =healthy group. Equal variances between groups observed in all measures

Higher means for the pathological group were observed for almost all the factors, but Intimate relationships avoidance, although for this last factor, we observed no significance or expressive effect size. However, considering these measures, only Attention seeking presented significant differences between groups. Three comparisons were significant, showing moderate effect sizes, and one factor (Interpersonal passivity) presented no significant differences, but the effect size can be viewed as small (but not negligible).

\section{Discussion}

Several criticisms are presented in previous literature regarding the categorical model for PDs (Esebec \& Echeburúa, 2015; Sarkar \& Duggan, 2010; Skodol et al., 2011; Samuel \& Griffin, 2015), and indicators of 
the benefits of the dimensional approach are presented (Anderson et al., 2014; Forbes et al., 2017; Hopwood et al., 2018; Krueger \& Markor, 2014; Morey et al., 2016). Born within the dimensional perspective, the HiTOP proposal (Kotov, Krueger, \& Watson, 2018; Kotov et al., 2017) has as one of the main objectives to advance with the taxonomy of mental disorders, including PDs and indicates which are the most relevant traits composing the diagnostic categories. Our goal with the present study was to develop the IDCP-Av, i.e., a specific version of IDCP-2 to measure typical traits of the AvPD according to the HiTOP. The findings should be interpreted as initial, and suggest that the IDCP-Av evaluate the main traits of the AvPD, considering both, the HiTOP and the literature focused on the disorder (Krueger et al., 2012; Lampe \& Malhi, 2018; Lynam et al., 2012; Sellbom et al., 2017; Shedler \& Westen, 2004; Weinbrecht et al., 2016).

Regarding the findings from step 1 , we observed that the interpersonal passivity traits were not covered by IDCP-2 (Carvalho \& Primi, 2019), although seen as relevant in HiTOP for the AvPD (Kotov et al., 2017). This trait is related to low assertiveness and passive behavior, identifying people showing difficulties in advocate for their thoughts and assume control (Lynam et al., 2012). After items development for this trait, along with Depressivity, Intimate relationships avoidance, Generalized avoidance, and Social isolation, IDCP-Av is represented by the substantial traits for AvPD according to HiTOP, which is corroborated by literature focusing on this PD (Butcher et al., 2001; Kotov et al., 2018; Krueger et al., 2012; Lampe \& Malhi, 2018; Lynam et al., 2012; Sellbom et al., 2017; Weinbrecht et al., 2016).

The psychometric properties of the IDCP-Av were investigated in step 2 . Although not having an a priori expectation of how factors of the scale should group, high consistency between variables was expected. The one-factor solution and the internal consistency coefficients suggest that IDCP-Av items are highly related, which is desired as a good indicator of unidimensionality (Hattie, 1985; Nunnally, 1978; Tavakol \& Dennick, 2011). Moreover, this factor, called Interpersonal Avoidance, seems to cover the AvPD core symptoms (Kotov et al., 2018; Krueger et al., 2014).

Specifically, on the developed factor, Interpersonal passivity, its correlation with the other factors was poor, which decreased the internal consistency and average correlation coefficients of the measure total score. These findings suggested the exclusion of this factor from the IDCP-Av. However, we relied also on the external validity (i.e., correlations with PID-5 and FFaVA, and group comparisons) to decision-making, as the discriminant capacity and the associations of the scale with external variables are better indicators of its applicability (APA, 2013).

Correlations between the IDCP-Av factors and the external measures, in general, were according to the expected (Table 1). Only two associations were moderated according to effect size guidelines (Cohen, 1992), Intimate relationships avoidance with Intimacy Avoidance, and Interpersonal passivity with Withdrawal. Further correlations were marginally moderated or small. Total score correlations were higher with Withdrawal from PID-5, indicating its closeness with the core of AvPD (Krueger et al., 2012; Lampe \& Malhi, 2018). Particularly attention was given to the Interpersonal passivity factor, considering its previous findings. However, it showed the higher observed correlation in Table 4 with one of the main AvPD traits (i.e., fear of approaching people), suggesting its suitableness to be held in the IDCP-Av.

The group comparison added to the investigation of the practical application of the IDCP-Av. In general, we observed a tendency to the pathological group in showing higher means in comparison to the healthy group. The two exceptions to it were not significant, i.e., Intimate relationship avoidance and Social isolation factors. Concerning the significant differences, higher means were always for the pathological group. Marked differences were observed for Depressivity, and Generalized avoidance, which is coherent as these are typical traits of the AvPD (Krueger et al., 2012; Lampe et al., 2017; Lampe \& Malhi, 2018; Weinbrecht et al., 2016). Although the Interpersonal passivity factor did not present the highest group differences, the observed effect sized can be considered as expressive while small (Sawilowsky, 2009).

We presented initial psychometric evidence of a specific version of the IDCP-2 for AvPD traits assessment, according to HiTOP. In general, the evidence corroborated the utility of the test. Our findings indicated the maintaining the Interpersonal passivity factor, as it presented good indicators of discriminant capacities, despite unsatisfactory finding on internal structure and consistency coefficients. Other studies must be carried on, mainly, using clinical samples and, specifically, people diagnosed with AvPD. Moreover, we must highlight that the community sample in this study was not assessed in order to assure that people considered as "healthy" indeed did not have AvPD or other PD diagnoses. Studies with diagnostic accuracy designs must be conducted seeking to establish a clinical cutoff for the IDCP-Av.

\section{References}

Abela, R. K., Carvalho, L. D. F., Cho, S. J. M., \& Yazigi, L. (2015). Validity Evidences for the Dimensional Clinical Personality Inventory in Outpatient Psychiatric Sample. Paidéia (Ribeirão Preto), 25(61), 221-228. doi:10.1590/1982-43272561201510 
Al-Dajani, N., Gralnick, T. M., \& Bagby, R. M. (2018). " A psychometric review of the personality inventory for DSM-5 (PID-5): Current status and future directions". Journal of Personality Assessment, 100(4), 448. doi: 10.1080/00223891.2018.1433405

American Psychological Association (2013). Manual Diagnóstico e Estatístico de Transtornos Mentais (DSM-V). Porto Alegre: Artmed.

Anderson, J. L., Sellbom, M., Bagby, R. M., Quilty, L. C., Veltri, C. O. C, Markon, E. K., \& Krueger, R. F. (2012). On the Convergence Between PSY-5 Domains and PID-5 Domains and Facets: Implications for Assessment of DSM-5 Personality Traits. Assessment 20(3), 286-294. doi: 10.1177/1073191112471141

Anderson, J., Snider, S., Sellbom, M., Krueger, R., \& Hopwood, C. (2014). A comparison of the DSM-5 Section II and Section III personality disorder structures. Psychiatry Research, 216(3), 363-372. doi: 10.1016/j.psychres.2014.01.007

Butcher, J. N., Graham, J. R., Ben-Porath, Y. S., Tellegen, A., Dahlstrom, W. G., \& Kaemmer, B. (2001). MMPI-2 (Minnesota Multiphasic Personality Inventory-2): Manual for administration, scoring, and interpretation (Rev. ed.). Minneapolis: University of Minnesota Press.

Carvalho, L. F., \& Arruda, W. (2016). Revisão da dimensão isolamento do inventário dimensional clínico da personalidade. Temas em Psicologia, 24(1), 47-61. doi: 10.9788/TP2016.1-04

Carvalho, L. F., \& Primi, R. (2019). Manual técnico do Inventário Dimensional Clínico da Personalidade-2 (IDCP-2). [Technical Manual of the Dimensional Clinical Inventory of Personality-2 (IDCP-2)]. São Paulo, SP: Pearson.

Carvalho, L. F., \& Primi, R. (2016). Prototype matching of personality disorders with the imensional Clinical Personality Inventory. Psicologia: Teoria e Pesquisa, 32(2), 1-9. doi: 10.1590/0102-3772e322214

Carvalho, L. F., \& Primi, R. (2015). Development and internal structure investigation of the Dimensional Clinical Personality Inventory. Psicologia: Reflexão e Crítica, 28(2), 322-330. doi: 10.1590/1678-7153.201528212

Carvalho, L. F., \& Sette, C. P. (2017). Revision of the Criticism Avoidance dimension of the Dimensional Clinical Personality Inventory. Estudos de Psicologia (Campinas), 34(2), 219-231. doi: 10.1590/1982-02752017000200004

Carvalho, L. F., Sette, C. P., \& Miguel, F. K. (2018). Investigation of the clinical functioning of the Dimensional Clinical Personality Inventory 2 criticism avoidance dimension. Trends in Psychiatry and Psychotherapy, 40(2), 93-103. doi: 10.1590/2237-6089-2017-0038

Carvalho, L. F. \& Silva, G. C. (2016). Review of the Self-sacrifice Dimension of the Clinical Dimensional Personality Inventory. Psicologia: Reflexão e Crítica, 29(6). doi: 10.1186/s41155-016-0022-z

Clark, L. A. (1990). Toward a consensual set of symptom clusters for assessment of personality disorder. In J. N. Butcher, \& C. D. Spielberger (Orgs.), Advances in personality assessment (pp. 243-266). New Jersey: Lawrence Erlbaum Associates.

Cohen, J (1992). "A power primer". Psychological Bulletin, 112(1), 155-159. doi:10.1037/0033-2909.112.1.155.

Conway, C. C., Forbes, M. K., Forbush, K. T., Fried, E. I., Hallquist, M. N., Kotov, R., ... \& Sunderland, M. (2019). A hierarchical taxonomy of psychopathology can transform mental health research. Perspectives on Psychological Science, 14(3), 419-436. doi: $10.1177 / 1745691618810696$

DeShong, H. L., Lengel, G. J., Sauer-Zavala, S. E., O’Meara, M., \& Mullins-Sweatt, S. N. (2015). Construct validity of the five factor borderline inventory. Assessment, 22(3), 319-331. doi: 10.1177/1073191114548029

Esbec, E. \& Echeburúa, E. (2015). The hybrid model for the classification of personality disorders in DSM-5: A critical analysis. Actas Españolas de Psiquiatría, 43(5), 177-86. Recuperado de https:/www.actaspsiquiatria.es/repositorio/17/97/ENG/17-97ENG-177-86-648616.pdf

Forbes, M. K., Kotov, R., Ruggero, C. J., Watson, D., Zimmerman, M., \& Krueger, R. F. (2017). Delineating the joint hierarchical structure of clinical and personality disorders in an outpatient psychiatric sample. Comprehensive Psychiatry, 79, 19-30. doi: 10.1016/j. comppsych.2017.04.006

Gore, W. L., Tomiatti, M., \& Widiger, T. A. (2011). The home for histrionism. Personality and Mental Health, 5(1), 57-72. doi: 10.1002/ pmh.151

Hattie, J. (1985). Methodology Review: Assessing Unidimensionality of Tests and ltems. Applied Psychological Measurement, 9(2), $139-164$. doi: 10.1177/014662168500900204

Hopwood, C. J., Kotov, R., Krueger, R. F., Watson, D., Widiger, T. A., Althoff, R. R., ... \& Bornovalova, M. A. (2018). The time has come for dimensional personality disorder diagnosis. Personality and Mental Health, 12(1), 82-86. doi: 10.1002/pmh.1408

Huprich, S. K. (2018). Moving beyond categories and dimensions in personality pathology assessment and diagnosis. The British Journal of Psychiatry, 213(6),685-689. doi: 10.1192/bjp.2018.149

Hopwood, C. J., Thomas, K. M., Markon, K., Wright, A. G. C., \& Krueger, R. F. (2012). DSM-5 Personality Traits and DSM-IV Personality Disorders. Journal of Abnormal Psychology, 121(2), 424-432. doi: 10.1037/a0026656

Kotov, R., Krueger, R. F., \& Watson, D. (2018). A paradigm shift in psychiatric classification: The Hierarchical Taxonomy of Psychopathology (HiTOP). World Psychiatry, 17(1), 24-25. doi: 10.1002/wps.20478

Kotov, R., Krueger, R. F., Watson, D., Achenbach, T. M., Althoff, R. R., Bagby, R. M., ... \& Eaton, N. R. (2017). The Hierarchical Taxonomy of Psychopathology (HiTOP): A dimensional alternative to traditional nosologies. Journal of Abnormal Psychology, 126(4), 454-477. doi: 10.1037/abn0000258

Krueger, R. F., Derringer, J., Markon, K. E., Watson, D., \& Skodol, A. E. (2012). Initial construction of a maladaptive personality trait model and inventory for DSM-5. Psychological Medicine, 42(9), 1879-1890. doi: 10.1017/S0033291711002674

Krueger, R.F., \& Markon, K. E. (2014). The Role of the DSM-5 Personality Trait Model in Moving Toward a Quantitative and Empirically Based Approach to Classifying Personality and Psychopathology. Annual Review of Clinical Psychology, 10(7), 477-501. doi: 10.1146/ annurev-clinpsy-032813-153732

Lampe, L., \& Malhi, G. S. (2018). Avoidant personality disorder: current insights. Psychology Research and Behavior Management ,11(2018), 55-66. doi: 10.2147/PRBM.S121073

Lynam, D. R., Loehr, A., Miller, J. D., \& Widiger, T. A. (2012). A five-factor measure of avoidant personality: The FFAvA. Journal of Personality Assessment, 94(5), 466-474. doi: 10.1080/00223891.2012.677886

Maj, M. (2018). Why the clinical utility of diagnostic categories in psychiatry is intrinsically limited and how we can use new approaches to complement them. World Psychiatry, 17(2), 121-122. doi: 10.1002/wps.20512

Marsh, H. W., Morin, A. J., Parker, P. D., \& Kaur, G. (2014). Exploratory structural equation modeling: An integration of the best features of exploratory and confirmatory factor analysis. Annual Review of Clinical Psychology, 10(3), 85-110. doi: 10.1146/annurevclinpsy-032813-153700 
Morey, L. C., Benson, K. T., \& Skodol, A. E. (2016). Relating DSM-5 section III personality traits to section II personality disorder diagnoses. Psychological Medicine, 46(s/n), 647-655. doi: 10.1017/S0033291715002226

Millon, T. (2011). Disorders of personality: Introducing a DSM/ICD spectrum from normal to abnormal (3rd ed.). Hoboken, NJ: Wiley.

Mullins-Sweatt, S. N., Edmundson, M., Sauer-Zavala, S., Lynam, D. R., Miller, J. D., \& Widiger, T. A. (2012). Five-factor measure of borderline personality traits. Journal of Personality Assessment, 94(5), 475-487. doi: 10.1080/00223891.2012.672504

Nunnally, J. C. (1978). Psychometric Theory. New York: McGraw-Hill.

Pianowski, G, Carvalho, L. F., \& Miguel, F. K. (2019). Investigating the Spectra constellations of the Hierarchical Taxonomy of Psychopathology (HiTOP) model for personality disorders based on empirical data from a community sample. Brazilian Journal of Psychiatry, 41(2), 148-152. doi: 10.1590/1516-4446-2018-0015

Santana, G., Coelho, B. M., Wang, Y. P., Filho, D. P. C., Viana, M. C., \& Andrade, L. H. S. G. (2018). The epidemiology of personality disorders in the Sao Paulo Megacity general population. PLoS ONE, 13(4), 1-20. doi: 10.1371/journal.pone.0195581

Sarkar, J. \& Duggan, C. (2010). Diagnosis and classification of personality disorder: Difficulties, their resolution and implications for practice. Advances in Psychiatric Treatment, 16(s/n), 388-396. doi: 10.1192/apt.bp.108.006015

Samuel, D. B., \& Griffin, S. A. (2015). A critical evaluation of retaining personality categories and types. In S. K. Huprich (Ed.), Personality disorders: Toward theoretical and empirical integration in diagnosis and assessment (pp. 43-62). Washington, DC, US: American Psychological Association. doi: 10.1037/14549-003

Sawilowsky, S. (2009). "New effect size rules of thumb". Journal of Modern Applied Statistical Methods, 8(2), 467-474.

Sellbom, M., Carmichael, K. L., \& Liggett, J. (2017). Examination of DSM-5 Section III avoidant personality disorder in a community sample. Personality and Mental Health, 11(4), 299-313. doi: doi.org/10.1002/pmh.1388

Shedler, J., \& Westen, D. (2004). Dimensions of personality pathology: An alternative to the five-factor model. American Journal of Psychiatry, 161(10), 1743-1754. doi: 10.1176/ajp.161.10.1743

Skodol, A. E., Morey, L. C., Bender, D.S., \& Oldham, J. M. (2015). The alternative DSM-5 model for personality disorders: A clinical application. American Journal of Psychiatry, 172(7), 606-613. doi: 10.1176/appi.ajp.2015.14101220

Skodol, A. E., Clark, L. A., Bender, D. S., Krueger, R. F., Morey, L. C., Verheul, R., ... \& Oldham, J.M. (2011). Proposed changes in personality and personality disorder assessment and diagnosis for DSM-5, Part I: Description and rationale. Personality Disorders: Theory, Research, and Treatment, 2(1),4-22. doi:10.1037/a0021891

Smith, G. T., McCarthy, D. M. (1995). Methodological considerations in the refinement of clinical assessment instruments. Psychological Assessment, 7(3), 300-308. doi:10.1037/1040-3590.7.3.300

Tavakol, M., \& Dennick, R. (2011). Making sense of Cronbach's alpha. International Journal of Medical Educational, 2(2011), 53-55. doi: $10.5116 /$ ijme.4dfb.8dfd

Tomiatti, M., Gore, W. L., Lynam, D. R., Miller, J. D., \& Widiger, T. A. (2012). A five-factor measure of histrionic personality traits. In N. Gotsiridze Columbus (Ed.), Psychological assessment (pp. 113-138). Hauppage, NY: Nova Science.

Weinbrecht, A., Schulze, L., Boettcher, J., \& Renneberg, B. (2016). Avoidant personality disorder: A current review. Current Psychiatry Reports, 18(3), 29. doi: 10.1007/s11920-016-0665-6

Widiger, T. A., \& Costa Junior, P. T. (2013). Personality disorders and the five-factor model of personality. Washington, DC, US: American Psychological Association.

Widiger, T. A., Lynam, D. R., Miller, J. D., \& Oltmanns, T. F. (2012). Measures to assess maladaptive variants of the five-factor model. Journal of Personality Assessment, 94(5), 450-455. doi: 10.1080/00223891.2012.677887

World Medical Association (2013). "Declaration of Helsinki: Ethical Principles for Medical Research Involving Human Subjects". JAMA, 310(20), 2191-2194. doi: 10.1001/jama.2013.281053.

Zimmerman, M. (2011). Is there adequate empirical justification for radically revising the personality disorders section for DSM 5? Personality Disorders: Theory, Research, and Treatment, 25(2), 206-221. doi:10.4088/JCP.11m06974

\section{Sobre os autores}

Lucas de Francisco Carvalho é psicólogo e Doutor em Psicologia pela Universidade São Francisco (USF, área de concentração Avaliação Psicológica). Atualmente é docente do programa de Pós-Graduação Stricto Sensu em Psicologia da USF, Campus Swift, Campinas/SP.

Adriana Satico Ferraz é psicóloga e Mestre em Psicologia pela Universidade São Francisco, Campus Swift, Campinas/SP. Atualmente é doutoranda em Psicologia pela mesma instituição de ensino, com bolsa da Fundação de Amparo à Pesquisa do Estado de São Paulo (FAPESP).

Fernanda Otoni é psicóloga e Mestre em Psicologia pela Universidade São Francisco, Campus Swift, Campinas/SP. Atualmente é doutoranda em Psicologia pela mesma instituição de ensino. 